\title{
FLUXOS, TRÂNSITOS E LUGARES DE (DES)ENCONTRO: CONTRIBUTOS PARA UMA LUSOFONIA CRÍTICA
}

\author{
Luís Cunha, Lurdes Macedo \& Rosa Cabecinhas
}

\begin{abstract}
Resumo
Enquanto conceito, a lusofonia é hoje olhada com justificada desconfiança por muitos lusófonos. Sendo impossível desligar esse conceito do lastro colonial que liga os países que têm o Português como língua oficial, importa, no entanto, não encerrar o debate nesse plano. Neste trabalho revisitamos algumas das narrativas fundacionais de uma identidade mitificada, como são as diferentes assombrações de um prometido Quinto Império ou o lusotropicalismo, tanto na sua fundação no Brasil quanto na sua reconstituição em Portugal. Por outro lado, procuramos pensar a lusofonia a partir da sua matriz formal: uma língua partilhada por diferentes povos em diferentes continentes. Também neste ponto o nosso objetivo é problematizar e densificar o debate, convocando para tal uma experiência singular de reflexão, concretamente a que é elaborada por Jorge de Sena já na reta final do Estado Novo. Partindo dessas focalizações, argumentamos sobre a possibilidade de a lusofonia comportar linhas de fuga a um certo reducionismo crítico, nomeadamente as que decorrem da circulação, convergente e divergente, de narrativas e de experiências singulares. Esta circulação de pessoas, ideias e memórias é potencialmente definidora de um espaço difuso e policentrado de efetiva interculturalidade sobre o qual importa refletir.
\end{abstract}

\section{FLOWS, TRANSITS AND (DIS)CONNECTION POINTS: CONTRIBUTIONS TOWARDS A CRITICAL LUSOPHONY}

\begin{abstract}
As a concept, Lusophony is today looked upon with justified suspicion by many Portuguese-speaking people. It is impossible to separate this concept from the colonial ballast that bounds the countries that have Portuguese as the official language. However, it is important to not end the debate on this plane. In this work we revisit some of the foundational narratives of a mythical identity, such as the different hauntings of a promised Quinto Império or Lusotropicalism, both in its founding in Brazil and in its reconstitution in Portugal. On the other hand, we discuss about Lusophony from its formal matrix: a language shared by different peoples in different continents. Our objective is to problematize and deepen the debate, summoning a unique experience of reflection, concretely the one that is elaborated by Jorge de Sena already in the final stretch of Estado Novo. Based on these focuses, we argue about the possibility of Lusophony to include lines of escape from certain reductionisms, namely those that derive from the convergent and divergent circulation of narratives and singular experiences. This circulation of people, ideas and memories, is potentially defining a diffuse and polycentric space of effective interculturality, which nurtures further reflection.
\end{abstract}

KEYWORDS

Lusophony; culture; interculturality; exceptionalism; singularity 


\section{UNIVERSALISMO E PARTICULARISMO: FACES DA CULTURA ${ }^{1}$}

Se no final da década de 1950 era ainda com conviç̧ão que Raymond Williams (1958) discutia as fronteiras culturais considerando que o âmbito de uma cultura era geralmente proporcional à área de uma língua, hoje tal associação revela-se insustentável. Não só porque o inglês extravasou as dilatadas fronteiras onde se afirmou como língua oficial, tornando-se numa espécie de latim vulgar de uma nova ordem cultural imperial, mas também porque o incremento do fluxo de pessoas e ideias evidenciou a impossibilidade de continuar a acreditar naquilo que sempre fora uma ilusão: a conciliação entre a ordem política, plasmada no Estado soberano, e a ordem cultural, tal como o nacionalismo imaginou, e imagina ainda, ser vivenciada pelos cidadãos que coexistem num território a que se convencionou chamar nação. Evidentemente que este princípio de segmentação da cultura, fazendo-a reportar a uma língua ou conferindo-lhe um conteúdo étnico, é ele próprio, assumidamente, parcial. Para retomar uma distinção que o mesmo Raymond Williams desenvolve com proveito, pode dizer-se que quando se confere destaque à língua estamos a privilegiar a cultura enquanto construtora de identidades distintas e potencialmente concorrentes (Eagleton, 2000). Porém, a esta ênfase no particularismo contrapõe-se, com igual sucesso, um entendimento integrado da cultura, quer dizer, a visão da cultura como produto comum de uma Humanidade que se desenvolve de acordo com um desígnio que, em última instância, configuraria a vitória da razão universal. Esta visão dicotómica e complementar daquilo a que chamamos cultura parece hoje demasiado esquemática e claramente insuficiente para dar conta da complexidade de um conceito excessivamente banalizado.

Oscilando entre o caminho universal, garantido pela convicção de uma razão vencedora delineada pelo projeto iluminista, e a virtude de uma distinção étnica disciplinada, quer dizer, contida dentro das fronteiras dos diferentes Estados-nação, o projeto nacionalista parecia garantir à Humanidade um sólido ponto de equilíbrio. De algum modo, o que nos era oferecido era uma possibilidade de conciliação da grande narrativa, capaz de formatar uma História Universal a partir de diferentes cambiantes e registos, com as narrativas nacionais e mesmo com narrativas regionais, mais ou menos folclorizadas. Foi sempre um frágil e ilusório equilíbrio, bem como uma idealização perigosa, em nome da qual se legitimaram limpezas étnicas, eufemisticamente consideradas como uma forma de assegurar a preservação das identidades nacionais através de um ideal de convergência entre território, povo e cultura.

$\mathrm{Na}$ segunda metade do século $X X$ toda esta frágil arquitetura de conveniência se desmoronou de vez. Os territórios que integravam os impérios coloniais europeus tornaram-se nações independentes, também elas preocupadas em construir a sua própria narrativa legitimadora (Chakrabarty, 2000). Um dos aspetos desse complexo processo de construção narrativa é apontado por Ferro (2004) quando destaca que a história ensinada às crianças africanas tende a glorificar o esplendor dos grandes impérios existentes no seu continente antes da chegada de europeus, reforçando essa valorização do

\footnotetext{
' Investigação desenvolvida no contexto do projeto "Memories, cultures and identities: how the past weights on the present-day intercultural relations in Mozambique and Portugal?", financiado pela Rede Aga Khan para o Desenvolvimento e pela Fundação para a Ciência e Tecnologia.
} 
passado ao contrapor-lhe o atraso e a decadência da Europa feudal da mesma época. Trata-se, de resto, de uma estratégia narrativa que foi também sinalizada na análise do conteúdo dos manuais de história em uso corrente no ensino secundário em Moçambique (ver Cabecinhas, Macedo, Jamal \& Sá, 2018). Em paralelo a este exercício de autoconstrução identitária, os fluxos migratórios - tanto para as antigas metrópoles como para outros países em acelerado crescimento económico - produziram um efeito divergente, senão mesmo contraditório. De facto, sobretudo após a II Guerra Mundial e em grande medida na decorrência do surgimento de novos estados independentes, assistiu-se ao incremento de fluxos migratórios que vieram dar às cidades europeias de maior dimensão uma nova face. O que a uns parecia exotismo e a outros cosmopolitismo, expressou uma nova atmosfera, inevitavelmente dissonante do ideal de homogeneidade cultural das nações (Portes, 2006) e, nesse sentido, contribuindo para desconstruir a ideia de uma identidade perene associada à cultura nacional.

As respostas dadas pelas antigas metrópoles a esta crescente recomposição étnica das suas populações foram diferentes, balizando-se entre dois extremos: de um lado, a procura de uma dinâmica assimilacionista, assente numa ideia de integração suportada, em última instância, na crença da superioridade civilizacional do Ocidente; no outro lado, a ideia de relativismo cultural foi tomada como referência para políticas públicas, que acabaram conduzindo ao que pode ser chamado de multicuralismo funcional. De uma forma necessariamente simplificada, podemos ver no primeiro caso a solução francesa e no segundo a inglesa, mas em qualquer dos casos, incluindo as propostas mais matizadas, do que se tratava era de responder aos desafios pós-coloniais. As dificuldades que a Europa enfrenta no presente parecem demonstrar que nenhuma das soluções conseguiu resolver satisfatoriamente esses desafios. A França laica e republicana confrontou-se, nas últimas décadas, com aquilo que parece ser um retrocesso no processo de integração dos imigrantes, ao mesmo tempo que o relativismo cultural britânico se revelou, afinal, um "monoculturalismo plural" (Sen, 2007), sempre sujeito à eclosão de fundamentalismos no seu seio.

Fora do espaço europeu, e na verdade fora desta equação mais imediatamente pós-colonial, os EUA representam um caso particular e irrepetível. O seu processo de constituição enquanto Estado, marcado por um consenso liberal em torno da ideia de cidadania e participação democrática, singularizou este território face a outras antigas colónias europeias mas também face aos congéneres europeus da mesma época (Catroga, 2005). Trata-se de um caso singular com consequências evidentes no modo como lida com a questão da diversidade cultural, na medida em que o elemento agregador, aquilo que habitualmente é designado por american way of life, gere os múltiplos modos de vida característicos da contemporaneidade americana atendendo mais a ideais de abolição de diferenças do que a ideais de valorização da diversidade (Beck, 2006). Esta via singular não deve ser confundida, bem entendido, com ausência de conflitualidade de raiz étnica e cultural. Ao contrário, também neste caso os processos de integração e de distinção étnica foram complexos e geradores de tensão, muito embora revelem diferenças estruturais significativas com os que se observam no contexto europeu (Wacquant, 2014). 
Portugal passou também por uma longa experiência colonial, profundamente estruturadora de muitas das narrativas com que se pensou enquanto país e que continuam a ser relevantes no período pós-colonial em que hoje vivemos. Um dos vetores recorrentes dessas narrativas foi a afirmação de uma excecionalidade quase sempre pouco discutida ou analisada. Voltaremos, mais adiante, a esta questão, mas importa, neste ponto, convocar um conteúdo expressivo, que é, simultaneamente, uma ideia e um projeto: a lusofonia. Ao discuti-la, procuraremos centrar o debate no modo como alguns dos tópicos centrais do argumento da excecionalidade foram reajustados à realidade pós-colonial, o que nos permitirá pensar as dinâmicas e as entorses que marcam a lusofonia enquanto projeto.

\section{LUSOFONIA: DO CONCEITO À SUA OPERACIONALIZAÇÃO}

Em primeiro lugar, deve ficar claro que a lusofonia tem sido glosada em diferentes tons e modelações. A uma mesma palavra correspondem entendimentos muito diversos, que podem ir desde aqueles que veem a lusofonia como uma ameaça neocolonial num mundo que se imagina pós-colonial, até àqueles que veem nela um projeto pragmático de ampliação de possibilidades a nível internacional de uma língua comum a vários países (Cunha, 2015a). Entre estes dois extremos, que projetam o mesmo conceito numa linha maximalista ou minimalista, define-se uma vasta arena onde se confrontam diferentes atores, individuais e institucionais, configurando um debate que tem diversas centralidades analíticas, que ora se excluem e colidem, ora convergem estrategicamente. Estas diferentes centralidades decorrem do confronto de distintas tradições disciplinares e consequente disputa em torno das fronteiras que demarcam campos científicos, a que acresce uma relevante inscrição política que igualmente fragmenta o objeto - por um lado associando-o a uma longa tradição que essencializa a excecionalidade do coIonialismo português; por outro desconstruindo criticamente o conceito de lusofonia, propondo, em última análise, a sua rejeição. De alguma forma, estes confrontos conceptuais tornam a lusofonia numa categoria útil para pensar as ideias de cultura e diversidade cultural na modernidade tardia.

Neste sentido, procurando fazer deste trabalho mais uma peça para o longo debate que acabámos de convocar, propomo-nos pensar a lusofonia enquanto categoria difusa e declaradamente conflituante, não para nos posicionarmos em qualquer dos eixos centrais do debate; antes, pelo contrário, para tentarmos explorar os seus interstícios como linhas de fuga. Se a centralidade da língua em qualquer projeto lusófono é inquestionável, a verdade é que a tensão ideológica dificulta qualquer ambição de neutralidade neste campo. Importa, por isso, matizar o confronto. À ideia de que a lusofonia é um espaço de convergência sem hierarquias, assegurada pelas virtudes da comunicação intercultural, deve agregar-se a evidência de que há sempre assimetrias de poder nas relações entre grupos sociais e entre os valores culturais que os enformam (Cabecinhas \& Cunha, 2017; L. Macedo, 2013). Por outro lado, não negando o lastro histórico produzido pelo processo colonial, não permitir que as suas cicatrizes impeçam a definição 
de espaços onde se confrontem ideias e experiências singulares, ora convergindo ora divergindo, sempre acrescentando algo para um enriquecimento comum. Para melhor o situarmos no presente, é sempre possível e útil fazer uma arqueologia do confronto e da convergência de narrativas identitárias, na condição de resistirmos à simplificação e ao esquematismo ${ }^{2}$. Do mesmo modo, algumas experiências singulares deixaram um rasto que importa recuperar, igualmente sem dispensar o olhar crítico nem ceder à simplificação. Começaremos, justamente, por este ponto, para depois nos ocuparmos da persistência de algumas narrativas identitárias. Em ambos os casos a nossa intenção é essencialmente ilustrativa, não permitindo qualquer leitura sistémica.

\section{Jorge de Sena e a “cultura da língua”}

Foi já no final do Estado Novo, em julho de 1972, que Jorge de Sena, em visita de trabalho a Moçambique, teceu considerações públicas sobre as questões que aqui nos ocupam. Convém, desde já, sinalizar que esta visita protagonizada por um intelectual proscrito pelo regime a uma então colónia portuguesa constituiu um verdadeiro acontecimento fraturante, não só por oferecer um programa evocativo do IV centenário da primeira publicação d'Os Lusíadas alternativo ao das comemorações oficiais que simultaneamente decorriam sob a égide do Governador $\mathrm{Geral}^{3}$, como sobretudo pelas ideias defendidas por Jorge de Sena durante as quatro conferências que proferiu e nas poucas mas expressivas entrevistas que concedeu aos média locais (L. Macedo, 2017a). Ligado a Moçambique pela amizade que alimentava através de intensa correspondência com alguns dos intelectuais e dos artistas da então Lourenço Marques, bem como pela colaboração que mantinha com a revista de poesia Caliban ${ }^{4}$, Jorge de Sena chamou a atenção para a situação da língua portuguesa no mundo - à época, a sexta com maior número de falantes e, prospetivamente, a quarta até ao final do século XX - e para o problema que, em sua opinião, era urgente resolver: segundo palavras suas, "a magnitude e o peso do nosso idioma são largamente ignorados no mundo"5, o que conduzia, por exemplo, à dificuldade de reconhecimento internacional das produções culturais em língua portuguesa ${ }^{6}$.

\footnotetext{
${ }^{2} \mathrm{O}$ debate que hoje se faz em torno do projeto de construção de um museu dedicado à expansão/descobertas é bem elucidativo da atualidade da questão e também do esquematismo simplificador com que tende a ser abordada.

${ }^{3}$ O programa das comemorações oficiais do IV Centenário da primeira publicação d'Os Lusíadas encontra-se amplamente documentado na imprensa da época em Moçambique, sendo este essencialmente composto por eventos institucionais (jantares de gala, salvas de morteiros, ...) que decorreram ao longo de vários dias.

${ }^{4}$ A revista de poesia Caliban foi editada por João Pedro Grabato Dias (alter ego literário do artista plástico António Quadros) e por Rui Knofli entre 1971 e 1972, tendo por objetivo central a divulgação da poesia de língua portuguesa produzida na época, sobretudo aquela que era produzida fora de Portugal. Para além de Jorge de Sena, colaboravam com esta revista autores como José Craveirinha, Rui Nogar e Herberto Hélder (à época, residente em Angola). A Caliban, um dos primeiros projetos independentes de cultura da língua, foi encerrada pela Administração Colonial no mês anterior à visita de Jorge de Sena.

5 Entrevista concedida ao jornal Notícias de 16 de julho de 1972, p. 10.

${ }^{6}$ A exceção era a obra de Camões, sobretudo Os Lusíadas, na qual Jorge de Sena era um dos mais reconhecidos especialistas a nível mundial. Fazendo uso da sua vasta experiência internacional, o intelectual português demonstrou, em entrevista concedida à Rádio Clube de Moçambique a 19 de julho de 1972, que a epopeia de Camões era alvo de interesse em todo o mundo pelo seu valor literário e não por ser uma narrativa de exaltação das glórias da expansão portuguesa.
} 
O então professor da Universidade de Santa Bárbara, na Califórnia - onde havia chegado após um período de exílio no Brasil e uma fugaz passagem por Wisconsin - foi apontando, ao longo das suas intervenções, as causas do problema, bem como os seus possíveis remédios. A apropriação da língua pelos gramáticos portugueses ${ }^{7}$, a propagação da ideia de que existem formas mais corretas de falar a língua do que outras ${ }^{8}$, a deficiente relação cultural entre Portugal e o Brasil ${ }^{9}$, bem como o não reconhecimento da produção cultural das então colónias portuguesas ${ }^{10}$ - o que, em sua opinião, não invalidava que Rui Knopfli fosse um dos maiores poetas e Eugénio Lisboa fosse um dos maiores críticos literários de língua portuguesa desse tempo - seriam, a seu ver, as principais razões para a fragmentação daquilo a que chamava a "cultura da língua". Para além do diagnóstico, Jorge de Sena foi apontando, através de sugestivas metáforas e de estimulantes truques de retórica, aqueles que considerava serem os remédios para esses males: desmitificar o passado histórico e ultrapassar o nacionalismo português (L. Macedo, 2017a). Quer isto dizer que a "cultura da língua", concebida por Sena como a cultura em língua portuguesa, da qual ninguém é legítimo proprietário e cuja dimensão extravasa a dimensão dos países onde esta é falada, não pode ser pensada senão depois de uma rigorosa revisitação da história, capaz de repor a verdade dos factos, bem como depois de Portugal e os portugueses deixarem de se imaginar como epicentro privilegiado dessa cultura. O que Jorge de Sena defendia era, pois, uma "cultura da língua" fundada no conhecimento científico da história e num multiculturalismo agregador.

\section{Centralidade da língua No PRojeto lusófono}

O colonialismo português teve, sem dúvida, as suas singularidades, ainda que estas não sejam as que habitualmente lhe são apontadas. Ao invés de imaginarmos um colonialismo predominantemente benigno, feito por um povo com natural vocação evangelizadora, isento de racismo ou de práticas de exploração, devemos pensar a sua singularidade na decorrência de especificidades históricas concretas. Assim, a crença, acrítica, num colonialismo intrinsecamente bom, deve dar lugar à visão mais realista de um colonialismo periférico e subalterno (Santos, 2001). Algumas das consequências dessa subalternidade - baixo capital financeiro, ausência de um projeto colonial centralizado e coerente, predominância de relações informais, etc. - virão a constituir argumentos de sustentação da visão lusotropical, que não escapa, todavia, a uma evidente essencialização. Do que se trata, então, não é de rejeitar a singularidade do colonialismo

\footnotetext{
7 "É uma outra verdade de que em Portugal muita gente ainda não se convenceu: as línguas pertencem a quem as fala e a quem as escreve - não aos gramáticos" (Notícias, 16 de julho de 1972, p. 10).

8 "Os povos não falam bem, nem mal: falam. E, se eles não falassem, a língua não havia!" (Notícias, 16 de julho de 1972 , p. 10).

9 “Em Portugal não se põem os escritores brasileiros nas selectas, que é para as pessoas não se contaminarem daquela gramática horrível; e, no Brasil, não se põem os escritores portugueses para que não se pense que os escritores portugueses estão a colonizar o Brasil outra vez. O que é, evidentemente, uma situação mutuamente ridícula". Entrevista à Rádio Clube de Moçambique, 19 de julho de 1972.

10 "Terei a oportunidade de visitar a Ilha de Moçambique, um dos únicos lugares - juntamente com Lisboa - onde podemos ter a certeza que Camões esteve" (Notícias, 16 de julho de 1972, p. 10).
} 
português nem da experiência pós-colonial, mas de pensar esses fenómenos sem o habitual lastro ideológico, esteja este fundado na vocação evangelizadora, na disponibilidade para a miscigenação, na aptidão natural para lidar com povos tropicais, ou em quaisquer outros pronunciamentos sem suporte objetivo.

O facto de o português ser uma língua partilhada por povos dispersos pelo planeta deve-se, evidentemente, ao processo colonial. A sua expansão foi, em primeiro lugar, fruto da vontade soberana, e, nesse sentido, da tentativa de impor o uso de uma mesma língua nas distintas partes de um império. Porém, a afirmação dessa língua comum foi também o resultado, dir-se-ia que paradoxal, do processo de descolonização e consequente criação de novas unidades políticas. Se no primeiro caso a língua do colonizador foi uma imposição etnocêntrica e uma estratégia de domínio da periferia pelo centro, no segundo caso essa mesma língua foi o cimento indispensável para a criação de uma unidade política a partir de uma fragmentação étnica pré-colonial, ainda que por vezes reforçada pela gestão colonial. Naturalmente que em cada um dos territórios colonizados, e que são hoje os países constituintes da Comunidade de Países de Língua Portuguesa (CPLP), estas regras gerais foram aplicadas de forma diversa. Pesam nestas diferenças razões históricas, sociais e políticas, mas no que diz respeito à política da língua, certo é que a convergência se foi fazendo em torno do português.

Mesmo em torno do uso de uma língua comum, o consenso é mais postulado que efetivo, não só pela coexistência da língua oficial com inúmeras línguas nacionais, mas sobretudo porque a língua não pode deixar de ser um campo de disputa, que não apenas confronta a antiga metrópole com os novos países, mas que se afirma também como instrumento de poder dentro de cada espaço e em relação aos grupos que o compõem. Pelo lugar que ocupa dentro do espaço lusófono, vale a pena considerar, ainda que brevemente, o caso brasileiro. Ao longo dos três séculos de percurso histórico do Brasil-colónia, a coexistência das várias línguas faladas pelas diversas gentes que habitavam o seu território foi sendo progressivamente eliminada até à definitiva afirmação do português enquanto língua nacional. Tal processo constituiu, sem dúvida, um gigantesco glotocídio, indissociável dos processos de dominação colonial, mas também dos processos internos que deram cidadania ao português. De facto, como notou Eduardo Lourenço (2004, p. 123), a expansão da língua portuguesa pelo mundo "foi algo mais e mais importante" do que o resultado "da violência colonizadora clássica", uma vez que "por benfazejo acaso, os Portugueses, mesmo na sua hora imperial, eram demasiado fracos para 'imporem', em sentido próprio, a sua língua [sic]”. Apenas apelando a um olhar pluridisciplinar se poderia avançar no entendimento dos processos históricos e culturais que levaram à consolidação de uma língua num determinado território. Pela parte que nos toca limitar-nos-emos a deixar uma breve nota sobre a importância da interculturalidade nesses processos.

Teyssier (2007) observava que, em terras de Vera Cruz do século XVI, as populações de origem indígena, africana ou mestiça iam aprendendo o português falado pelos colonos, embora o fizessem de forma "imperfeita". Paralelamente, alguns colonos, bem como a sua descendência, adquiriam também mestria quanto aos falares das 
populações autóctones o que lhes permitia retirar dividendos a partir da facilidade em comunicar com o outro. De acordo com Schwartz (1999, p. 60),

portugueses e mestiços, leigos e clérigos que falavam línguas indígenas tinham, em geral, orgulho desse seu predicado e empenhavam-se em apregoá-lo à Coroa e a outras autoridades, uma vez que era uma habilidade necessária e valiosa no século XVI e início do século XVII.

Ao mesmo tempo, desenvolvia-se na colónia uma língua geral com base num tupi simplificado e gramaticalizado pelos missionários jesuítas que, ao sobrepor-se a todos os idiomas desse tronco, viria a tornar-se num código de ampla utilização. Sobre as origens desta língua, Houaiss (1984/1992, p. 53) reparava que "desde o início da catequese do gentio, no século XVI, ficou patente aos missionários jesuíticos que não seria através de sua própria língua (...) que a catequese poderia ser levada a cabo". Assim, as necessidades de comunicação conduziram os missionários, homens doutos num saber que mais tarde haveria de se denominar por linguística, a uma prática viva que emergia de contactos interétnicos e que disciplinava as várias línguas faladas pelos diferentes grupos de ameríndios. As possibilidades pragmáticas oferecidas por esta língua geral, que colocava em interação não só portugueses com indígenas como também indígenas entre si, propiciaram o seu rápido sucesso, fazendo do português uma língua quase exclusiva dos colonos, dos centros urbanos e de outros lugares onde se encontrava implantado o poder.

Como observava Holanda (1936/2010), foi deste modo que, durante muito tempo, o português e a língua geral viveram lado a lado como línguas de comunicação. O Brasil conhecia, então, um bilinguismo que empurrava cada vez mais para a marginalidade os idiomas conservados por certos povos locais e as línguas africanas trazidas pelos escravos ${ }^{11}$. Embora Serafim da Silva Neto afirmasse, na sua clássica e monumental História da língua portuguesa (1952, p. 52), que “a história de uma língua não é um esquema rigorosamente pré-estabelecido, não é um problema algébrico", apresentava, ao mesmo tempo, várias tendências comuns às situações de bilinguismo. Consideremos apenas duas delas: um longo período em que se trava uma luta pela supremacia; a vitória decidida pelo prestígio, pelo valor utilitário, pela glória literária e pela situação social dos falantes. Mesmo sem álgebra à mistura, foi o que aconteceu no Brasil da centúria de Oitocentos. Conforme descrito por Teyssier (2007), vários acontecimentos ocorridos nesse período viriam a determinar o cenário para o triunfo do Português sobre a língua geral. Por um lado, a chegada de grandes contingentes de portugueses atraídos pela descoberta de minas de ouro e de diamantes aumentava o número de glotas da língua do poder, com ganhos consequentes no seu uso utilitário. Por outro lado, o Marquês de Pombal promulgava, em 1753, uma lei que proibia o uso da língua geral e oficializava a obrigatoriedade de utilização do Português no Brasil. O golpe de misericórdia na língua

\footnotetext{
"Segundo Teyssier (2007), as línguas africanas mais faladas no Brasil colonial foram o ioruba (importado do território correspondente à atual Nigéria) e o quimbundo (importado de Angola). Embora seja difícil avaliar a real influência destas línguas no português que hoje se fala no Brasil, é inegável que as mesmas deixaram as suas marcas, nomeadamente a nível vocabular.
} 
geral seria finalmente dado, em 1759, com a expulsão dos jesuítas do território brasileiro, afastando da colónia os seus principais protetores. Enfatizando o impacto do processo de "relusitanização" do Rio de Janeiro com a transferência da corte de D. João VI, em 1808, que traria cerca de 15.000 portugueses para a nova capital do império, o autor conclui que cinquenta anos depois da partida dos patronos da língua geral, o Português tinha-a eliminado completamente, restando dela algumas marcas, sobretudo a nível vocabular. É neste cenário que, poucos anos mais tarde, em 1822, se dá a independência do Brasil enquanto nação. Sem que outra alternativa se colocasse, coube à língua portuguesa constituir-se como sua língua nacional.

Apesar do Português ter assumido no Brasil tal estatuto desde a independência de 1822, a verdade é que nem sempre a questão linguística foi pacífica entre as elites intelectuais do país. Sobrinho (1958/2000) analisava as divergências em torno das características próprias da língua portuguesa usada no Brasil no primeiro século pós-independência, identificando três posições predominantes, a saber: 1) a afirmação da existência de uma língua brasileira autónoma, tendo esta em Monteiro Lobato ${ }^{12}$ seu mais acérrimo defensor; 2) a alegação da formação de um dialeto brasileiro a partir do Português europeu que justificava as diferenças de fonética, de prosódia e de morfologia entre os dois falares; 3) por fim, a defesa de que as diferenças entre a língua falada no Brasil e em Portugal não autorizavam a ideia da existência de dialetos ou subdialetos brasileiros, uma vez que as mesmas se verificavam sobretudo ao nível da pronúncia. Contudo, Sobrinho sublinhava que a prevalência da língua portuguesa, em relação às suas múltiplas linguagens, constituía um dos principais fundamentos da unidade nacional de um país tão imenso como o Brasil. Em boa verdade, esta é a tese que tem vingado ao longo do tempo, muito embora a identidade brasileira continue a contrapor-se à identidade portuguesa por via dos diferentes usos da mesma língua.

\section{NARRATIVAS IDENTITÁRIAS: PERSISTÊNCIA E MUDANÇA}

Como já se disse, não se ambicionando uma leitura sistémica, procuraremos, ainda assim, revisitar de forma ilustrativa a arqueologia dos processos discursivos através dos quais cultura e identidade se projetam como argumentos centrais em processos políticos de longa duração. A tentação de enquanto portugueses nos olharmos a partir de uma convicção de excecionalidade vem de longe e tem sido amplamente glosada (Vecchi, 2010). Deu o mote, por exemplo, para Eduardo Lourenço (1992) escrever Psicanálise mítica do destino português, texto que se tornou referencial. Outros autores e textos, anteriores e posteriores a este que evocamos, pegaram também neste tema, de tal forma que a ideia da exceção lusa se tornou numa espécie de buraco negro que tudo absorve

\footnotetext{
${ }^{12}$ Monteiro Lobato (1882-1948) foi um dos mais importantes escritores brasileiros do seu tempo, tendo obtido enorme sucesso no campo da literatura infanto-juvenil. O Sítio do Pica-Pau Amarelo conta-se entre as suas obras mais conhecidas (Dicionário das Literaturas Portuguesa, Galega e Brasileira, 1960). Nacionalista convicto e avesso a todas as formas de "europeização", Lobato defendia a existência de uma língua brasileira autónoma da língua portuguesa. Porém, como observa Sobrinho (1958/2000, p. 66), a sua tese obedecia a um "silogismo um tanto simplista e precário", uma vez que se apoiava na ideia de que, assim como o português surgiu da corrupção do latim, também o brasileiro surgia da corrupção do português.
} 
- mesmo as considerações críticas acabam sendo integradas numa meta-narrativa, gerando novas versões atualizadas da exceção, de que um conhecido best-seller do filósofo José Gil (2004) é exemplo. Umas das peças fundamentais desta secular reivindicação de excecionalidade foi o projeto colonial/imperial, que nas diferentes configurações que foi assumindo desde o século XV, não escapou a narrativas fundadas na ideia de excecionalidade. Algumas são bastante remotas, como o sonho do Quinto Império, que de resto se foi renovando; outras são mais recentes, mas nem por isso menos centrais ao debate, como todo o edifício conceptual do lusotropicalismo.

A ideia messiânica de um Quinto Império, formulada inicialmente pelo Pe. António Vieira no século XVII, e reatualizada mais tarde por Fernando Pessoa e por Agostinho da Silva, já no século XX, ilustra bem o modo como a ideia de excecionalidade acabou por estruturar fortemente a narrativa acerca de quem somos. Encontra as suas raízes no mito bíblico da interpretação feita por Daniel de um enigmático sonho de Nabucodonosor, rei da Babilónia. De acordo com essa interpretação, após quatro reinos terrenos e perecíveis que traduziam a queda e a degradação da Humanidade, haveria de surgir, por vontade de Deus, um quinto reino universal e intemporal para a salvar. O jesuíta português tomou esta passagem da Bíblia, reinterpretando-a no contexto de um mundo que, pela primeira vez, apresentava uma dimensão planetária, reunindo condições de extensão e de duração para o aparecimento de um novo e definitivo estádio, ou seja, - Quinto Império. Antes das navegações portuguesas dos séculos XV e XVI, nenhum império poderia estender-se a toda a Terra, nem garantir a completude e a eternidade que haviam sido preconizadas por Daniel. Reunidas essas condições, o Quinto Império surgiria para unir todos os povos sob o mesmo estádio civilizacional através da evangelização empreendida pelos portugueses, superando a crise da Humanidade. Como essa crise tinha origem no velho mundo da Europa, o Pe. António Vieira centrou esse quinto reino no Brasil, uma parcela do mundo ainda incorrupta e na qual ainda muito havia para descobrir (Franco, 2007). É nestas formulações que Calafate (2006, p. 61) interpreta, no pensamento de Vieira, um "sonho de harmonia e paz universais" que emerge de uma conceção "da história ecuménica fortemente impregnada pelo movimento, pela transformação, pela novidade", na qual os portugueses assumem o papel de povo eleito no horizonte da ação humana, rumo a um outro futuro: o de um novo e último estádio, em que os seres humanos saem de si mesmos para viver para o mundo.

Esta reabilitação providencial da Humanidade seria retomada por Fernando Pessoa, embora com contornos mais abstratos, perdendo a sua inserção na geografia e a sua possibilidade de aplicação no tempo histórico. Assim, em Pessoa, o Quinto Império constitui-se como um mito'3 ou uma visão da alma (Franco, 2007), numa crítica radical à existência daqueles que vivem felizes na sua pequena casa e no seu pequeno quintal'14.

\footnotetext{
${ }^{13}$ Sinde (citado em Pessoa, 1934/2007, p. 5) nota que Fernando Pessoa procurava recuperar o mito como forma de compreensão da história nacional. Neste sentido, afirma o autor: "Fernando Pessoa entendia o mito como o verdadeiro impulsionador da História (...), o que lhe confere sentido, o que dá realidade ao destino das nações e dos indivíduos".

${ }^{14}$ Esta crítica de Fernando Pessoa está claramente expressa no poema "Quinto Império", contido na obra Mensagem, do qual se apresentam alguns versos mais ilustrativos: "Triste de quem vive em casa / Contente com o seu lar / Sem que um sonho, no erguer da asa / (...) /Ser descontente é ser homem / Que as forças cegas se domem / Pela visão que a alma tem!" (Pessoa, 1934/2007, p. 89).
} 
Neste sentido, Calafate (2006) observava que, em Pessoa, a elevação da alma conducente ao Quinto Império passa pela aspiração à "extremosidade das alturas", lugar acima da mediania, reservado apenas a santos e a heróis.

Com a releitura deste mito por Agostinho da Silva, regressa-se à necessidade de um projeto histórico que reatualize a concretização geográfica e a reflexão civilizacional. A visão deste pensador sobre a quinta idade do mundo gravitava em torno das escolhas dos seres humanos na modernidade, sendo esta a quarta das idades. A modernidade poderia vitimar a Humanidade na longa luta fratricida que caracteriza a história ou, em alternativa, poderia elevá-la na plenitude de uma civilização universal, sem fomes e sem opressões (Franco, 2007). Apesar de se tratar de uma escolha a fazer, todo o pensamento de Agostinho afirma o primado da vida sobre a morte, pelo que não é suposto que o futuro se prefigure numa idade inerte. Pelo contrário, a quinta idade, que reuniria todos os povos, teria uma escala planetária e contaria com um contributo decisivo da comunidade de língua portuguesa, à qual caberia a missão de unificar o mundo pelo espírito. Procurando sintetizar a proposta de Agostinho da Silva sobre o último dos estádios da Humanidade, afirmava Freixo (2007, p. 24):

nesta nova era, a língua portuguesa desempenharia um papel fundamental por ser falada em todas as partes do globo e representar o símbolo da expansão portuguesa que lançou as bases da construção do "novo mundo", do "Reino do Espírito". Nesta nova ordem, o Brasil teria um papel fundamental, pois traria em si os elementos do verdadeiro Portugal, aquele Portugal arcaico que se perdeu com o fracasso histórico da nação. Para ele, em sua utopia, o Brasil é a concretização do sonho do Quinto Império, é a Ilha dos Amores de Camões, o Não-Lugar capaz de ser o centro de uma nova civilização por ser o ponto de encontro de diversas culturas, onde a miscigenação favoreceu a tolerância e a moderação.

A refundação do mito de Vieira por Agostinho da Silva decorre, desde logo, da modificação das circunstâncias históricas. Se em Vieira Portugal pode assumir por inteiro o papel de protagonista no projeto utópico, o tempo em que Agostinho da Silva escreveu já não o permite. Em todo o caso, em ambos os autores, o Quinto Império projeta o ideal de uma idade final, perene e feliz, na qual Portugal e o Brasil cumprem a missão messiânica de unir a Humanidade num mesmo estádio civilizacional. Entre a agregação em torno de uma envangelização de cunho português (Vieira) ou sustentada numa língua e culturas partilhadas constitutivas de uma lusitanidade desterritorializada (Agostinho da Silva), fica evidente uma continuidade narrativa que sedimenta uma visão mitificada de uma identidade coletiva.

O lusotropicalismo, cunhado por Gilberto Freyre, constitui um outro referencial importante no argumento da excecionalidade portuguesa, contribuindo também, de forma determinante, para a narrativa identitária de que vimos falando. Reportado à reta final da história colonial portuguesa e ideologicamente apropriado pelo regime do Estado Novo, importa perceber, antes de mais, que o lusotropicalismo foi uma teoria que 
começou por pensar e legitimar a nação brasileira, vincando uma unidade cultural sobreposta à unidade política, contrariando a desconfiança nas possibilidades de um novo país visto, à época, como perigosamente miscigenado. Esta génese da teoria lusotropicalista é relevante, na medida em que, nascendo na periferia e devendo ser enquadrada no longo processo fundacional de uma nação difusa e de dimensão continental (Ribeiro, 1995), se vê apropriada e transmutada em narrativa legitimadora de uma velha metrópole acossada pelos ventos da descolonização europeia (Cunha, 2015b). Neste ponto, mais do que repetir aqui os argumentos do sociólogo brasileiro, julgamos útil sublinhar esta inversão simbólica da ordem centro/periferia, já que ela sinaliza, num plano diferente do habitualmente glosado, a singularidade do projeto colonial português - periférico e subalterno face às grandes potências europeias.

No que diz respeito à contribuição do lusotropicalismo para o debate em torno de uma identidade lusófona, importa ter presente as muitas críticas que sofreu por parte de intelectuais portugueses e brasileiros, muito embora não possa deixar de visto também como uma das poucas teorias interpretativas do colonialismo português (Sousa, 2001). O argumento central de Freyre assenta na valorização dos processos de mestiçagem "racial" e cultural em espaços colonizados por portugueses - pensando inicialmente no Brasil mas depois estendendo a apreciação positiva a outros territórios - defendendo a originalidade do projeto colonial português, perspetivando-o de acordo com um desenvolvimento "não dentro de uma rígida exclusividade de raça ou mesmo de cultura, mas por meio de constante interpenetração de valores culturais diversos e de abundante miscigenação" (Freyre, 1940, p. 12). As críticas que lhe foram feitas denunciavam que a miscigenação racial fora sempre mais falocrática que democrática e que a integração de elementos culturais africanos, ameríndios ou orientais nos hábitos dos povos hoje lusófonos obedecera a interesses predominantemente económicos - o que esclarece regimes de aculturação que não foram inteiramente recíprocos. Em contraponto a estas críticas continuou a ser sublinhada a ideia de excecionalidade, ainda que matizada: a mestiçagem e o hibridismo alcançados, sem que tivessem sido politicamente projetados, constituem heranças perenes de muitas das sociedades fundadas em espaços que outrora estiveram sob exploração colonial portuguesa.

O que subjaz a estas duas metanarrativas, e é nesse sentido que elas nos importam aqui, é a possibilidade de discutir a ideia de identidade cultural a partir da relação entre universalidade e particularismo. No caso de Vieira e Agostinho da Silva, estamos perante um particularismo que ambiciona universalizar-se; no caso de Freyre trata-se de postular a possibilidade de absorver a diversidade a partir de uma identidade singular. Ambas as narrativas necessitam da crença numa excecionalidade para se tornarem convincentes, pelo que importa considerar analiticamente o conceito. O problema que o excecionalismo coloca não reside, evidentemente, na singularidade de cada nação em confronto com as suas congéneres. Os contextos geográfico e histórico determinam singularidades objetivas mais ou menos expressivas. O problema coloca-se quando a reivindicação de exceção se faz com base em juízos morais: a nossa colonização não só foi diferente como foi melhor no plano moral. Trata-se de um problema, desde logo, por pensar as identidades 
a partir de uma matriz essencialista, desenhando uma alma coletiva autêntica e intemporal. Foi o pensamento conservador, que podemos situar politicamente à direita, quem acabou por se apropriar desta ideia de exceção revestida de conteúdo moral, ao mesmo tempo que um olhar à esquerda, mais crítico, rejeitou o essencialismo e, por extensão, também a ideia de exceção. Seguindo um outro percurso, também as correntes pós-coloniais se empenharam na rejeição dos particularismos, preferindo tratar o fenómeno colonial de uma forma global, seguindo uma linha de pensamento fundada por Edward Said (1978). De algum modo, e com perdão do plebeísmo, há nesta matéria o risco de deitar fora a criança com a água do banho. Não negando as singularidades, do que se trata é de olhar as diferenças de forma historicamente situada, extirpando-as dos conteúdos morais, que sempre acabam conduzindo a indesejáveis essencialismos.

\section{ENTRE CONVERGÊNCIA E DIVERGÊNCIA: O PODER DAS NARRATIVAS}

Tal como vimos argumentando, a lusofonia distingue-se de outras experiências pós-coloniais não por força de qualquer essência, mas por força de circunstâncias históricas que determinaram a natureza das relações entre a metrópole e os territórios colonizados e entre os diferentes grupos que em cada território se confrontaram. A dominação material e simbólica foi historicamente precária e casuística e dependeu sempre mais dos agentes envolvidos que de uma estrutura de poder consolidado. É justamente a fragilidade do colonialismo português, revelada na comparação com outros regimes coloniais, que torna a lusofonia útil para pensar os desafios inerentes à comunicação intercultural nos dias de hoje, nomeadamente os riscos de as relações pós-coloniais disfarçarem a perpetuação de relações assimétricas de poder (Cabecinhas \& Cunha, 2017; I. Macedo, 2016; L. Macedo, 2017b; Martins, 2017).

Para tal, deveremos ser capazes de resistir a ver na lusofonia um lugar de conciliação, um ilusório ponto de encontro dos povos que couberam em sorte ao colonialismo português. Importa, isso sim, considerá-la como um lugar de cruzamento de narrativas alimentadas pela história tanto quanto pela memória. Será, nesse sentido, um lugar de encontro, mas também de desencontro, ou seja, um ponto de cruzamento de narrativas convergentes e divergentes. Recuperemos o que atrás se disse acerca do lusotropicalismo: teoria académica, construída com uma intenção doméstica, isto é, que procurava explicar a identidade brasileira e legitimar uma unidade sobre a diversidade, acabou sendo apropriada e reorientada para uma outra função, a de justificar a permanência do domínio colonial em África por parte de Portugal. Recuperámo-la, para fazer notar que a teoria desenvolvida por Freyre se alimentou de um conteúdo narrativo que, enquanto tal, transcende as fronteiras do Brasil, podendo ter livre curso em Portugal ou ainda noutros territórios coloniais. Sendo certo que a teoria evoluiu e que na sua leitura existiram variações de ênfase ou mesmo de sentido, essas dinâmicas não implicaram a rejeição mas antes uma acomodação da narrativa. Assim, ao longo de décadas, sobretudo no Brasil e em Portugal, o lusotropicalismo, sem deixar de ser uma projeção fantasiosa, pôde funcionar como fio reconhecível que criou redes e teias de união e de dissenso. 
Neste mesmo sentido da existência de um espaço narrativo difuso, contraditório, conflituoso mas, ainda assim, gerador de dialética, podemos convocar outros exemplos. Veja-se o modo como o cristianismo, deixado como herança colonial em Timor, se incrementou após a saída de Portugal do território, sendo reinterpretado como uma das raízes matriciais da reivindicação de independência face à Indonésia (Sousa, 2001). A um outro nível, a guerra de libertação/colonial, ponto óbvio de tensão e conflito, constitui também um nó narrativo à volta do qual se estruturam memórias partilhadas ainda que divergentes (Cabecinhas \& Cunha, 2017). Um outro novelo denso de narrativas comuns, é-nos dado pela experiência migratória, que na verdade atravessa todo o espaço que a lusofonia configura (Abadia, Cabecinhas, Cunha \& Macedo, 2018). No caso de Portugal, o peso da emigração não qualificada, inclusive para países que foram antigas colónias, é ilustrativo da singularidade do colonialismo português nos pontos que atrás foram referidos - subalternidade e periferia. Encarado de outra forma, porém, ele ganha um inesperado significado, tornando-se num recurso narrativo disponível para a construção de memórias partilhadas, fermento para uma lusofonia que não seja apenas espaço de convergência económica nem tampouco a expressão recomposta de uma relação convencional entre centro e periferia. Ao contrário, que possa ser um espaço policêntrico, complexo, atravessado de múltiplos sinais, capaz de convocar diferentes povos e distintas experiências nacionais em torno de uma interculturalidade efetiva (Lopes, 2015; Martins, 2015).

\section{BREVE NOTA PARA UM FINAL INCONCLUSIVO}

Retomamos aqui a distinção, que reportámos a Raymond Williams, entre o universalismo, que assenta num entendimento da cultura como civilidade, e o valor do particularismo, que vê a cultura como produto e produtora de identidade. Fazemo-lo para argumentar que é justamente para a fronteira entre estas duas categorias que importa trazer o debate, sobretudo num tempo em que todo o espaço - físico, cultural, étnico, financeiro... - parece investido por categorias associadas à ideia de fronteira. Ambivalência, mistura e liminaridade, estão entre essas categorias, tal como está, também, a ideia de artificialidade, que é contrariada e se naturaliza através da discursividade e da prática. Se as fronteiras políticas são cicatrizes da história, linhas demarcatórias que ao longo do tempo, e mais nuns casos que em outros, se foram tornando mais profundas, criando territórios efetivamente distintos, o mesmo processo pode ser observado nas fronteiras culturais, quer elas sejam pensadas a partir de uma língua tornada nacional, quer reportem a outros vínculos históricos e culturais.

Como em todas as fronteiras, também nestas se reforçam ou esbatem diferenças. O debate entre singularidade e excecionalidade, que acima evocámos, deve ser pensado a partir desta premissa, forma de perceber como a objetificação da primeira se confunde com a imprecisão da segunda. De facto, se a singularidade pode ser vista de forma objetiva, como decorrência de processos históricos e sociais concretos e aferíveis, já a excecionalidade remete para critérios difusos, frequentemente associados a uma suposta 
essência identitária. Importa, por isso, distinguir os dois planos, única forma de superar o impasse entre a crítica ao essencialismo identitário e a possibilidade de aprofundar experiências concretas de interculturalidade. De algum modo foi o que aqui tentámos fazer, quer apelando à arqueologia de algumas das narrativas centrais que fundam uma suposta cultura e identidade lusófona, quer convocando uma experiência singular de reflexão em torno dessa matéria, concretamente a de Jorge de Sena em Moçambique, quer ainda da sugestão da existência de um conjunto de narrativas que atravessam o espaço lusófono interligando os seus diferentes povos. A tentativa de substituir excecionalidade por singularidade e de o fazer através do valor heurístico de situações concretas, não significa, evidentemente, isentar de crítica essas experiências de interculturalidade. Do que se trata, isso sim, é de explorar um conjunto de possibilidades de relação que se definem intersticialmente, quer dizer, no espaço difuso deixado vago pelas relações formais entre Estados-nação.

Falar de lusofonia, tal como falar de francofonia, de hispanofonia ou da Commonwealth, significa abordar um mesmo fenómeno, embora expresso em diferentes modulações (Margarido, 2000). Reportando a representações e conteúdos que definem laços formais e informais entre as antigas metrópoles e os territórios que um dia colonizaram, em tais expressões está contido o consenso pós-colonial possível tanto quanto a sua crítica. Em alguns casos, como acontece com a CPLP, existe uma instância formal que gere politicamente esse consenso, mas não pode ser perdido de vista que o debate se estende muito para lá desse plano. Para lá do acordo em torno de uma política da língua; para lá também de quaisquer entendimentos no que diz respeito a formas de cooperação económica, à ideia de lusofonia continuarão a corresponder sentimentos, experiências, memórias, expectativas. O perigo não está propriamente no reconhecimento de um passado partilhado mas na ambição de ver nessa suposta comunhão os traços de uma identidade comum. Importa, ao contrário, valorizar tanto as linhas de divergência quanto as de convergência, trocando a ideia de identidade convergente pela de enriquecimento mútuo. Reforça-se, dessa forma, a partilha de experiências singulares, que apenas se tornam reconhecíveis pela língua comum e por traços de memória e de história - nuns casos de cooperação, noutros de conflito - com os quais se pode fundar um património que não tem pátria nem centro, pertencendo a todos os que constroem a sua identidade a partir da língua portuguesa.

\section{REFERÊNCIAS}

Abadia, L., Cabecinhas, R., Macedo, I. \& Cunha, L. (2018). Interwoven migration narratives: identity and social representations in the lusophone world. Identities - Global Studies in Culture and Power, 25(3), 339357. DOI: 10.1080/1070289X.2016.1244062

Beck, U. (2006). Qu'est-ce le cosmopolitisme? Paris: Éditions Aubier.

Cabecinhas, R. \& Cunha, L. (2017). Da importância do diálogo ao desafio da interculturalidade. In R. Cabecinhas \& L. Cunha (Eds.), Comunicação intercultural: perspectivas, dilemas e desafios (pp. 7-12). Vila Nova de Famalicão: Húmus. 
Cabecinhas, R., Macedo, I., Jamal, C. \& Sá, A. (2018). Representations of European colonialism, African resistance and liberation struggles in Mozambican history curricula and textbooks. In K. van Nieuwenhuyse \& J. P. Valentim (Eds.), The colonial pasts in history textbooks. Historical and social psychological perspectives (pp. 217-237). Charlotte, NC: Information Age Publishing.

Calafate, P. (Ed.) (2006). Portugal como problema. Séculos XVII e XVIII, da obscuridade profética à evidência geométrica (Volume II). Lisboa: Fundação Luso-Americana e Público.

Catroga, F. (2005). Nação, mito e rito. Religião civil e comemoracionismo. Fortaleza: Edições Nudoc-UFC/ Museu do Ceará.

Chakrabarty, D. (2000). Histórias de minorias, passados subalternos. In M. R. Sanches (Ed.), Deslocalizar a Europa. Antropologia, arte, literatura e história na pós-colonialidade (pp. 209-230). Lisboa: Livros Cotovia.

Cunha, L. (2015a). Liminaridade e descentramento: identidades lusófonas e suas narrativas. In M. L. Martins (Ed.), Lusofonia e interculturalidade - promessa e travessia (pp. 113-127). Vila Nova de Famalicão: Húmus.

Cunha, L. (2015b). O Luso no Trópico, ou por que não pode Olinda ser Olanda. In M. Cardão \& C. Castelo (Eds.), Gilberto Freyre. novas leituras do outro lado do Atlântico (pp. 61-78). São Paulo: Edusp.

Dicionário das Literaturas Portuguesa, Galega e Brasileira (1960). Direção de Jacinto do Prado Coelho. Porto: Livraria Figueirinhas.

Eagleton, T. (2000). A ideia de cultura. Lisboa: Temas \& Debates.

Ferro, M. (2004). Comment on raconte l'histoire aux enfants à travers le monde (nouvelle édition revue). Paris: Éditions Payot.

Franco, A. C. (2007). Nótula sobre o Quinto Império em Agostinho da Silva. Revista Convergência Lusíada, 23, 55-62. Retirado de http://www.realgabinete.com.br/portalweb/portals/o/documentos/revista23.pdf

Freixo, A. (2007). A língua portuguesa como utopia: Agostinho da Silva e o ideal da comunidade lusófona. Revista Convergência Lusíada, 23, 21-27. Retirado de http://www.realgabinete.com.br/portalweb/ portals/o/documentos/revista23.pdf

Freyre, G. (1940). O mundo que o português criou: aspectos das relações sociais e de cultura do Brasil com Portugal e as colônias portuguesas. Rio de Janeiro: José Olympio.

Gil, J. (2004). Portugal, hoje. O medo de existir. Lisboa: Relógio d’Água.

Holanda, S. B. (1936/2010). Raízes do Brasil. São Paulo: Companhia das Letras.

Houaiss, A. (1984/1992). O Português no Brasil. Rio de Janeiro: Editora Revan.

Lopes, A. J. (2015). Política linguística: terra de ninguém, terra de todos. Notas a partir de um Posto de Observação Moçambicano. In M. L. Martins (Ed.), Lusofonia e interculturalidade - promessa e travessia (pp. 197-226). Vila Nova de Famalicão: Húmus.

Lourenço, E. (1992). O labirinto da saudade. Psicanálise mítica do destino português. Lisboa: Dom Quixote.

Lourenço, E. (2004). A Nau de Ícaro seguido de imagem e miragem na lusofonia. Lisboa: Gradiva.

Macedo, I. (2016). Os jovens e o cinema português: a (des)colonização do imaginário? Comunicação e Sociedade, 29, 271-290. DOI: 10.17231/comsoc.29(2016).2420 
Macedo, L. (2013). Da diversidade do mundo ao mundo diverso da lusofonia: a reinvenção de uma comunidade geocultural na sociedade em rede. Tese de doutoramento em Ciências da Comunicação - Especialização em Comunicação Intercultural, Universidade do Minho, Braga, Portugal. Retirado de http:// repositorium.sdum.uminho.pt/handle/1822/28851

Macedo, L. (2017a). Desmitificar o passado e ultrapassar o nacionalismo para o desenvolvimento de uma cultura de língua portuguesa: o contributo de Jorge de Sena. In E. B. Rosa \& M. E. Prado (Eds.), Atas do XII Colóquio Internacional Tradição e Modernidade no Mundo Ibero-Americano. Rio de Janeiro: Rede Sirius; Porto, Portugal

Macedo, L. (2017b). Sobre o "Jardim das Delícias" como modelo de análise dos processos de comunicação intercultural. Comunicação e Sociedade, 31, 225-238. DOI: 10.17231/comsoc.31 (2017).2614

Margarido, A. (2000). A lusofonia e os lusófonos: novos mitos portugueses. Lisboa: Edições Universitárias Lusófonas.

Martins, M. L. (2015). Lusofonias - reinvenção de comunidades e combate linguístico-cultural. In M. L. Martins, (Ed.), Lusofonia e interculturalidade - promessa e travessia (pp. 7-23). Vila Nova de Famalicão: Húmus.

Martins, M. L. (2017). Comunicação da ciência, acesso aberto do conhecimento e repositórios digitais o futuro das comunidades lusófonas e ibero-americanas de Ciências Sociais e Humanas. In M. L. Martins (Ed.), A internacionalização das comunidades lusófonas e ibero-americanas de Ciências Sociais e Humanas o caso das Ciências da Comunicação (pp. 19-58). Vila Nova de Famalicão: Húmus.

Neto, S. S. (1952). História da língua portuguesa. Rio de Janeiro: Livros de Portugal.

Pessoa, F. (1934/2007). Mensagem. Porto: Porto Editora.

Portes, A. (2006). Imigração e metrópole: reflexões sobre história urbana. In Estudos sobre as migrações contemporâneas. Transnacionalismo, empreendedorismo e a segunda geração (pp. 19-45). Lisboa: Fim de Século.

Ribeiro, D. (1995). O povo brasileiro. A formação e o sentido do Brasil. São Paulo: Editora Schwarcz.

Said, E. (1978). Orientalismo. O Oriente como invenção do Ocidente. São Paulo: Editora Schwarcz.

Santos, B. S. (2001). Entre Próspero e Caliban: colonialismo, pós-colonialismo e inter-identidade. In M. I. Ramalho \& A. S. Ribeiro (Eds.), Entre ser e estar: raízes, percursos e discursos da identidade (pp. 24-85). Porto: Afrontamento.

Schwartz, S. B. (1999). Segredos internos. Engenhos e escravos na sociedade colonial. São Paulo: Companhia das Letras.

Sen, A. (2007). Identidade e violência. A ilusão do destino. Lisboa: Tinta da China.

Sobrinho, B. L. (1958/200o). A língua portuguesa e a unidade do Brasil. Rio de Janeiro: Nova Fronteira.

Sousa, I. C. (2001). The Portuguese colonization and the problem of East Timorese Nationalism. Lusotopie, 183-194. Retirado de https://www.persee.fr/doc/luso_1257-0273_2001_num_8_1_1439

Teyssier, P. (2007). História da língua portuguesa. São Paulo: Martins Fontes.

Vecchi, R. (2010). Excepção Atlântica. Pensar a literatura da guerra colonial. Porto: Afrontamento.

Wacquant, L. (2014). Marginalidade, etnicidade e penalidade na cidade neoliberal. Uma cartografia analítica. Tempo Social, 26(2), 139-164. DOI: 10.1590/S0103-20702014000200009 
Williams, R. (1958). Culture and society. Londres: Penguin Books.

\section{NOTAS BIOGRÁFICAS}

Luís Cunha é doutorado em Antropologia, membro integrado do CRIA e professor do Departamento de Sociologia do Instituto de Ciências Sociais da Universidade do Minho. A sua investigação tem-se orientado em torno de diversos temas tais como a problemática das identidades nacionais, a memória social em contexto de fronteira, colonialismo e pós-colonialismo e mais recentemente sobre a crise dos sistemas financeiros e suas representações.

ORCID: https://orcid.org/oooo-0002-9940-9265

Email: Imcunha@ics.uminho.pt

Morada: Instituto de Ciências Sociais, Universidade do Minho, Campus de Gualtar, 4710-057 Braga

Lurdes Macedo é doutorada em Ciências da Comunicação, com especialização em Comunicação Intercultural, pela Universidade do Minho. É investigadora do Centro de Estudos de Comunicação e Sociedade desta universidade, onde trabalha nas áreas de Comunicação Intercultural e da Comunicação para o Desenvolvimento ao abrigo de uma bolsa de pós-doutoramento da FCT. Foi co-editora do Anuário Internacional de Comunicação Lusófona em 2010 e 2011, e do ebook Interfaces da Lusofonia em 2014. Tem várias dezenas de trabalhos publicados em revistas científicas nacionais e internacionais. Foi membro da comissão organizadora e/ou comissão científica de vários congressos internacionais. É também colaboradora eventual de várias publicações na área da cultura em Portugal e no Brasil. É professora auxiliar na Universidade Lusófona Porto, onde leciona desde 2008.

ORCID: https://orcid.org/oooo-0002-1577-1313

Email:mlmacedo7ı@gmail.com

Morada: Centro de Estudos de Comunicação e Sociedade, Instituto de Ciências Sociais, Universidade do Minho, Campus de Gualtar, 4710-057 Braga

Rosa Cabecinhas é doutorada em Ciências da Comunicação (Psicologia Social). Atualmente é Diretora do Programa de Doutoramento em Estudos Culturais da Universidade do Minho.

ORCID: https://orcid.org/oooo-0oo2-1491-3420

Email: cabecinhas@ics.uminho.pt

Morada: Centro de Estudos de Comunicação e Sociedade, Instituto de Ciências Sociais, Universidade do Minho, Campus de Gualtar, 4710-057 Braga

\section{* Submetido: 15.05.2018}

* Aceite: 11.07.2018 